\title{
Association between life style factors and sub- fertility among women, attend two specials hospital for women in Colombo: A case control study
}

Munasinghe P.M Piyasenage ( $\nabla$ munasingheheo@gmail.com )

Department of Health, Western Province,

Balachandran Kumarendran -

Department of Family Medicine, Faculty of Medicine, University of Jaffna,

Chandani Denawaka -

Medical Officer of Health Office, Nugegoda, Department of Health, Western Province

Kosala Lakmal -

Department of Health, Western Province,

Kumari Illukpitiya -

Health Promotion Bureau, Ministry of Health,

\section{Research Article}

Keywords: Sub-fertility, physical activities, passive smoking, hobbies, odds ratio, chi-square

Posted Date: December 29th, 2020

DOl: https://doi.org/10.21203/rs.3.rs-134940/v1

License: (c) (1) This work is licensed under a Creative Commons Attribution 4.0 International License.

Read Full License 


\section{Abstract}

Background: Sub-fertility has become a dominant health issue among married couples, expecting a baby with impacting social, psychological, and financial consequences especially in developing countries. As well as life style factors, which cause to immense effect on reproductive health has been changing dramatically at present. This study accordingly determines the association between life style factors and sub-fertility of women.

Method: 125 of case and 320 of control were enrolled. A pre tested structured questionnaire was used to collect the data through face to face interview. Chi-square, Man Whitney and independent sample T tests were performed (SPSS-22 version). Furthermore Odds Ratio (OR) was done for passive smoking and entertains with music. Result: The mean age at marriage was $25.1 \pm 3.1$ and $26.5 \pm 3$ for fertile sub-fertile women respectively. Vigorous and moderate physical activities were significantly high among sub-fertile than fertile $(P<0.05$ C.I 95\%), but total sitting time was not significantly different between two groups $(\mathrm{P}=0.16 \mathrm{Cl} 95 \%)$. Time of sedentary hobbies were high among fertile than sub-fertile $(\mathrm{P}=0.00 \mathrm{Cl} 95 \%)$. OR for passive smoking was $1.32 \mathrm{Cl} 95 \%$ and it was $0.6 \mathrm{Cl} 95 \%$ for entertainment with music. Invoking blessing of god is the most common religious practices among both groups.

Conclusion: This study demonstrated that the moderate physical activities and sedentary hobbies are not associated with fertility and second hand smoking has a negative effect while entertainment with music has a positive effect to the fertility.

\section{Background}

Every couple wants to bear a child but some of them need a medical intervention to have a child. Subfertility has become priority issue of the public health with affecting $10-15 \%$ of all couples in reproductive age globally(1).Furthermore it has been estimated that more than 70 million couples worldwide suffer from sub-fertility and majority of them live in developing countries(2). Although South Asia Region is the most densely populated region in the world the Total Fertility Rate (TFR) has declined from 4.2 in 1990 to 2.6 in 2012(3). Similarly, in spite of the substantial progression of the maternal and child health, one in six couple are sub-fertile in Sri Lanka(4).

Sub-fertility is defined as the failure to achieve the pregnancy after twelve months or more of regular unprotected sexual intercourse and it is classified as primary and secondary(5). Primary sub-fertility occurs when a couple has never been conceived and it affects the quality of life with psychological distress, social stigmatization, economic strain and family discord. Sub-fertility could result from a wide spectrum of abnormalities found in either partner or sometimes both including ovulatory disorders, tubal disease, endometriosis, chromosomal abnormalities, sperm factors, sexual dysfunctions and unexplained sub-fertility(6). In spite of clinical and genetic reasons, life style factors such as exercise, dietary patterns, smoking and mental stress have great impact on fertility for both male and females $(7,8)$. Life style factors 
are behavior and circumstances, that can be modified and contribute to improve the health and wellbeing of the people including fertility(7).

Although modification of life style factors, pave the way to increase the fertility, there are $86.8 \%$ sub-fertile women don't engage in a sport activity or exercise regularly in Sri Lanka. As well as one third of sub-fertile women are either overweight or obese(9). Premature deaths and morbidity due to chronic disease has increased dramatically due to unhealthy life style factors of the people in Sri Lanka(10). Hence there is a greater possibility that the same consequences have affected to the fertility of the people in Sri Lanka due to improper life style changes.

Under these circumstances it was imperative to study on association between modern life styles and subfertility of the women, who are expecting a baby. Physical activities (vigorous \& moderate), leisure time activities (sedentary \& physically active), exposure to the passive smoking and mental relaxing practices are the factors which have been studied.

Primary health care providers in Sri Lanka conduct more fertility awareness programmes for newly married couples in regular basis. Moreover they carry out individual counselling sessions for sub-fertile couples. Hence the finding of this study can be utilized to prioritize and specify the activities, pertaining to fertility, conducted by the divisional health authority in the country.

\section{Method}

2.1 Study design: This was a case control study and cases were sub-fertile women, attended to the subfertility clinic and control were pregnant women attended to the antenatal clinics. Study was conducted in CSHW and DSHW in Colombo -08. Only primary sub-fertile women for cases and pregnant women with parity one as well as without had any fertility issues were selected for control in the study. Women, with any chronic disease were excluded from the study. The total amount of women, recruited for the study was 425 and $105(25 \%)$ were sub-fertile and 320 (75\%) were fertile.

2.2 Data collection: Written informed concern was obtained and interview administrated questionnaire was used to collect the data by trained data collectors. International Physical Activity Questionnaire (IPAQ) which was validated to Sri Lanka is utilized to prepare the questionnaire and it was focused to collect the data on socio demographic, reproductive health, physical activities, sedentary hobbies, leisure time activities, passive smoking and mental relaxing practice of the participants $(11,12)$. Furthermore height and weight were measured to calculate the Body Mass Index (BMI) of the participants. Height was measured to the nearest $0.1 \mathrm{~cm}$ using a stadiometer (seca 813, telescopic height measurement). Weight was measured to the nearest $0.1 \mathrm{~kg}$ using a calibrated electronic scale (seca 813), and BMI was calculated as weight $/$ height $^{2}$. All measurements were taken by trained female data collectors.

Metabolic Equillent Task (MET) per week was calculated by multiplying duration (minutes per day) with frequency (days per week) and 6 and 4 for the vigorous and moderate activities respectively(13). Physical activities perform according to Occupation, exercise, sports, leisure time activities and day today activities 
were assessed. As well as time spend for sedentary hobbies were also calculated. Although brisk walking is under the category of moderate physical activity it was analyzed separately. Similarly television watching time was analyzed independently from sedentary hobbies because these two activities have great impact on fertility as well as overall health $(14,15)$. Moreover frequency of exposure to the second hand smoking at the home and work place was assessed. As well as involving of following activities were assessed according to total frequency, taken as follows.

\section{Table 1: Type of frequencies of mental relaxing practices of the participants}

\begin{tabular}{|c|c|c|c|c|c|c|}
\hline Serial & Activity & Type of $\mathrm{fl}$ & quency & & & Total \\
\hline 01 & Entertain with music & Daily & Weekly & ---- & & \\
\hline 02 & Religious activities ${ }^{*}$ & Daily & Weekly & Monthly & Annually & \\
\hline 03 & Social work & Weekly & Monthly & Quarterly & & \\
\hline 04 & Petting animal & Daily & Weekly & & & \\
\hline 05 & Going trip/ picnic & Monthly & Quarterly & Yearly & & \\
\hline 06 & $\begin{array}{l}\text { Meditation/ Praying/ Invoking blessing } \\
\text { of god }\end{array}$ & Daily & Weekly & Monthly & & \\
\hline 07 & Belief \& superstition & Daily & Weekly & Monthly & Annually & \\
\hline
\end{tabular}

*Offering flowers, chanting or listening of pirith \& special activities of ash Monday, holy Thursday, good Friday etc..

2.3 Data analysis: Data documentation sheet (code book) was prepared to make a QES file in Epidata. After that data were entered to the REC file and finally data were exported to the SPSS (22 version) for the analysis. Descriptive statistics including mean and standard deviation (SD) of quantitative variables were computed. P-value less than 0.05 were considered statistically significant. BMI was categorized in four groups. The subjects were categorized in to the following groups based on WHO criteria for Asians. It is the BMI less than 18.4 as "Underweight", 18.5 to $22.9 \mathrm{BMI}$ as "Normal", 23.0 to $24.9 \mathrm{BMI}$ as "Overweight" and BMI over 25 as "Obese"(16). Independent sample T - test was done to compare the mean age at marriage between two groups. Two -way Anova was done to compare the mean age at marriage between different ethnic groups of fertile and sub-fertile women. Fertile and sub-fertile groups ware compared for the BMI (test variable) and it was depicted with box plots. Shapiro- Wilk test indicated that data, pertain to the variable of vigorous and moderate physical activities, walking time, and total sitting time were not normally distributed $(p<.05)$. Therefore non parametric test (Man Whitney test) was performed to compare the mean ranks. Furthermore independent sample $T$ test was done for television watching time and total sedentary hobbies for two groups and two-way ANOVA was performed, including two explanatory variables (profession and fertility).

Moreover odds ratio was performed for two variables $(95 \% \mathrm{Cl})$, passive smoking and entertainment with music. Chi-squire test was performed $(95 \% \mathrm{Cl})$ for mental relaxing practices and religious observances 
with sub-fertility.

Ethical aspects: Ethical approval was obtained from Ethical Review Committee, Faculty of Medicine, University of Kelaniya, Sri Lanka.

\section{Results}

3.1 Characteristics of the participants: The response rate of fertile group was $100 \%$ and it was $95 \%$ for sub-fertile group. Basic characteristic of the study participants are shown in table 2 to 4 and socio demographic factors were described as numbers and percentages after univariate analysis. Mean age of fertile and sub-fertile women at the interview was $26.6 \pm 3$ and $31.7 \pm 4$ respectively. But average age at marriage for fertile women was $25.1 \pm 3$ and it was $26.5 \pm 3$ for sub-fertile women. Moreover there were $31.4 \%$ of sub-fertile women were in the oldest age category (35-39 years). Regarding the level of education, most of fertile and sub fertile women were $A / L$ qualified and represent in similar percentage in both groups (45). There were only $2.5 \%$ of women in fertile group who had the post graduate qualification and no any women in sub-fertile group such qualification.

Table 2: Characteristics of the sample by age, ethnicity, religion, level of education \& occupation 


\begin{tabular}{|c|c|c|c|c|c|}
\hline Variable & Category & Number & Percentage & Number & Percentage \\
\hline \multirow[t]{4}{*}{ Age } & $20-24$ & 92 & 28.7 & -- & - \\
\hline & $25-29$ & 162 & 50.6 & 41 & 39.1 \\
\hline & $30-34$ & 66 & 20.7 & 31 & 29.5 \\
\hline & $35-39$ & -- & -- & 33 & 31.4 \\
\hline \multirow[t]{3}{*}{ Ethnicity } & Sinhala & 202 & 63.1 & 83 & 79.4 \\
\hline & Tamil & 66 & 20.6 & 17 & 16.4 \\
\hline & Muslim & 52 & 16.3 & 5 & 4.2 \\
\hline \multirow[t]{4}{*}{ Religion } & Buddhism & 154 & 48.1 & 62 & 59 \\
\hline & Catholic & 71 & 22.2 & 24 & 22.9 \\
\hline & Islam & 52 & 16.3 & 5 & 4.8 \\
\hline & Hinduism & 43 & 13.4 & 14 & 13.3 \\
\hline \multirow[t]{4}{*}{ Education } & O/L \& below & 124 & 38.8 & 46 & 43.8 \\
\hline & A/L qualified & 146 & 45.6 & 48 & 45.7 \\
\hline & Graduate & 42 & 13.1 & 11 & 10.5 \\
\hline & Post Graduate & 8 & 2.5 & -- & -- \\
\hline \multirow[t]{5}{*}{ Occupation } & Self-Employment & 39 & 12.2 & 20 & 19.1 \\
\hline & House wife & 134 & 41.8 & 37 & 35.2 \\
\hline & Government & 47 & 14.7 & 14 & 13.3 \\
\hline & Private & 76 & 23.8 & 21 & 20 \\
\hline & Daily payment job & 24 & 7.5 & 13 & 12.4 \\
\hline
\end{tabular}

Table 3: BMI of the participants

\begin{tabular}{llrrrr}
\hline & & \multicolumn{2}{c}{ Fertile women $(\mathrm{n}=320)$} & Sub-fertile women $(\mathrm{n}=105)$ \\
\hline \multirow{2}{*}{ Variable } & Category & Number & Percentage & Number & Percentage \\
& Under Weight & 8 & 2.5 & $\ldots$ & $\ldots$ \\
\cline { 2 - 6 } & Normal weight & 121 & 37.8 & 69 & 65.7 \\
& Over weight & 95 & 29.7 & 25 & 23.8 \\
\hline & Obese & 96 & 30.0 & 11 & 10.5 \\
\hline
\end{tabular}


Table 4: Summary of the monthly income

\begin{tabular}{lrrrrr} 
& $1^{\text {st }}$ Quartile & Mean & Median & IQR & $3^{\text {rd }}$ Quartile \\
\cline { 2 - 6 } Fertile & 65000 & 78765 & 77500 & 25000 & 90000 \\
Sub-fertile & 65000 & 85809 & 85000 & 30000 & 95000 \\
\hline
\end{tabular}

When comparing the family planning methods sub-fertile women had higher usage of family planning than fertile (53.4 \& 35.6). Moreover oral contraception and condom were the commonly used methods by both groups (table-5). But the result of the T-test of years of sub-fertility and usage and not usage of family planning in sub-fertile group was 0.328 which is higher than standard alpha value (0.05).

Table 5: Family Planning method of the participants

\begin{tabular}{lrrrr}
\hline Methods & \multicolumn{3}{l}{ Fertile women $(\mathrm{n}=320)$} & Sub-fertile women $(\mathrm{n}=105)$ \\
\hline & Number & Percentage & Number & Percentage \\
Oral contraception & 67 & 20.9 & 28 & 26.7 \\
\hline Condom & 42 & 13.2 & 23 & 21.9 \\
\hline Dipoproveera & 3 & 0.9 & -- & -- \\
\hline Calendar method & 1 & 0.3 & -- & -- \\
\hline Withdrawal & 1 & 0.3 & -- & -- \\
\hline Loop & -- & -- & 5 & 4.8 \\
\hline No any method & 206 & 64.4 & 49 & 46.6 \\
\hline
\end{tabular}

Sub-fertile women were lack of full restful sleep (8 hours per night) and only $7.6 \%$ women had a restful sleep. But $56.6 \%$ of fertile women had restful sleep more than five days per week (table-6).

\section{Table 6: No of hours of sleeping at night of participants}

\begin{tabular}{lrrrr}
\hline No of days per week & \multicolumn{2}{l}{ Fertile women $(\mathrm{n}=320)$} & \multicolumn{2}{l}{ Sub-fertile Women $(\mathrm{n}=105)$} \\
\hline & Number & Percentage & Number & Percentage \\
One or less than 1 days & 27 & 8.4 & 32 & 30.5 \\
\hline 2- 4 days & 112 & 35 & 65 & 61.9 \\
\hline More than 5 days & 181 & 56.6 & 8 & 7.6 \\
\hline
\end{tabular}




\subsection{Result of the bivariate analysis:}

Independent sample $T$ test showed that age at marriage was not significantly different between fertile and sub-fertile groups (C.I 95\%, $P=.915)$. But it was significantly different according to ethnicity of fertile groups $(F=6.6$ and $P=.001)$. Turkey post test showed that between Sinhala and Muslim $(P=.001)$ and Tamil and Muslim ( $P=.024)$ had significant difference of age at marriage. In sub-fertile groups, there was no significant difference in age at marriage according to ethnicity.

Two way Anova result showed that there was no significant interaction between ethnicity and fertility on the mean age at marriage $(P=0.433)$ and it is illustrated by figure 1 . Independent sample t test indicated that there was no significant difference between the years of expecting a baby and postponement of the pregnancy in sub-fertile group (C.I 95\% p= .438).

BMI was significantly high $(\mathrm{p}=.036)$ among fertile women than sub-fertile. The average BMI was 23.4and 21.fertile and sub-fertile women respectively. The following box plots (figure-2) are the standardized way of display the distribution of data of two groups and there were no outliers and IQR was higher among fertile group.

The result of the Man Whitney test for physical activities and sitting time are showed in table -07 .

Table 7: vigorous \& moderate physical activities, walking time and sitting time of the participants

\begin{tabular}{lrrr}
\hline \multicolumn{4}{c}{ Mean Rank } \\
\hline Variable & Fertile $(\mathrm{n}=320)$ & Sub-fertile $(\mathrm{n}=105)$ & P-Value \\
Vigorous physical activities & 201 & 250 & .000 \\
\hline Moderate physical activities & 187 & 291.5 & .000 \\
\hline Walking & 206 & 233 & .027 \\
\hline Total sitting time & 208 & 227.6 & .16 \\
\hline
\end{tabular}

The result of the two-way ANOVA indicated that there was no any statistically significant interaction between professions and fertility state on the sedentary time of fertile and sub-fertile women $(P=0.535)$. Moreover figure 03 demonstrated that two lines are independently distributed.

OR of exposure to the second hand smoking and sub-fertility was $1.32(95 \% \mathrm{Cl})$ and OR between entertainment with music and sub-fertility was $0.6(95 \% \mathrm{Cl})$. The results of the chi-square test of going trip, petting animal and praying was higher than predetermined significant level $(0.05,95 \% \mathrm{Cl})$ table -8 . 
Table 8: Leisure time activities \& religious practices of the participants

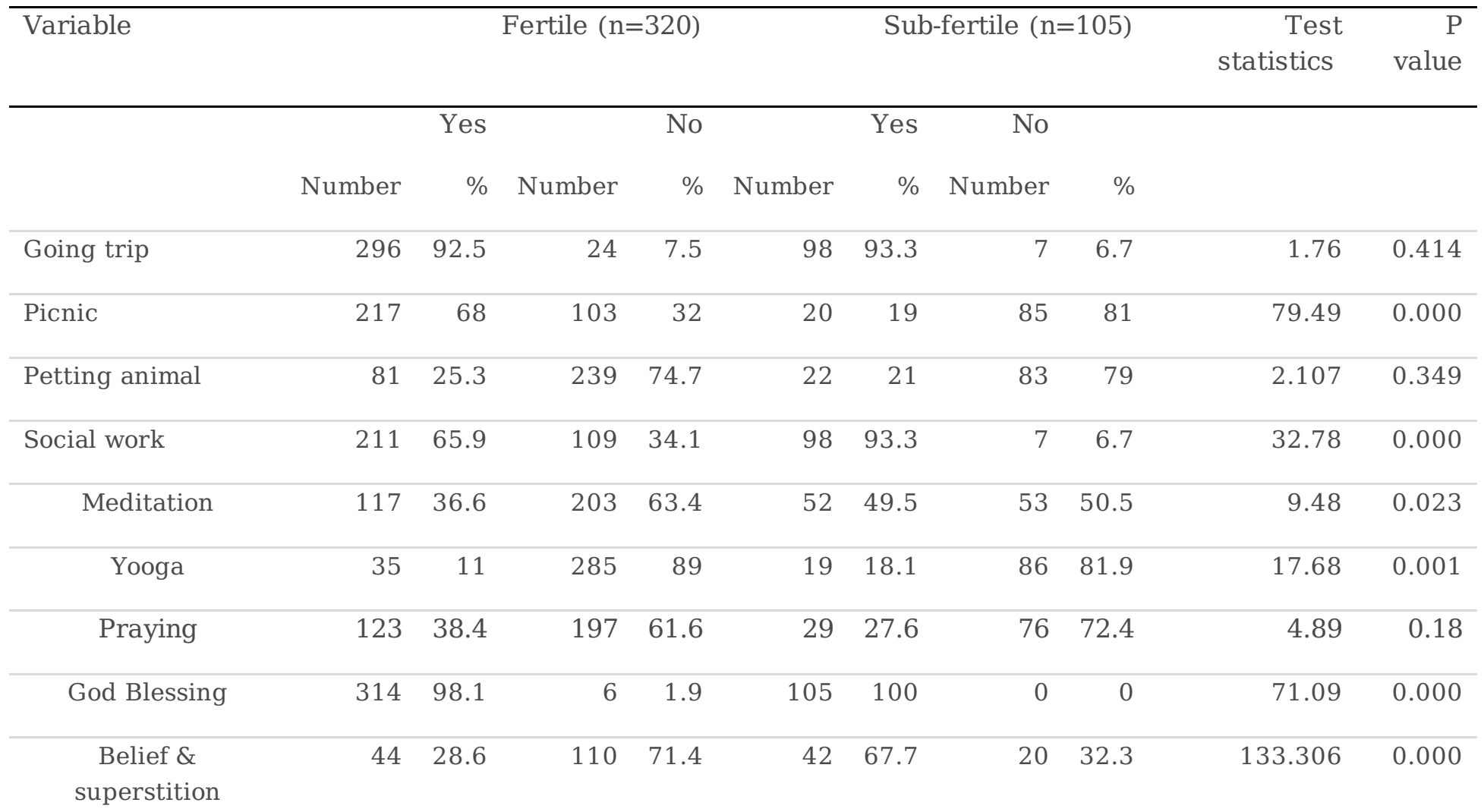

Most of religious and cultural practices were peculiar to certain religion and therefore chisquare tests were performed to both groups according to religion to know the association between religions and particular practices. The result was summarized in series of table 9 .

Table 9.1: Religious practice of Buddhist

\begin{tabular}{|c|c|c|c|c|c|c|c|c|c|c|}
\hline \multirow[t]{3}{*}{ Practice } & \multicolumn{4}{|c|}{ Fertile (154) } & \multicolumn{4}{|c|}{ Sub-fertile (62) } & \multirow{3}{*}{$\begin{array}{l}\text { Test } \\
\text { statistics }\end{array}$} & \multirow{3}{*}{$\begin{array}{l}\text { P- } \\
\text { Value }\end{array}$} \\
\hline & \multicolumn{2}{|c|}{ Yes } & \multicolumn{2}{|c|}{ No } & \multicolumn{2}{|c|}{ Yes } & \multicolumn{2}{|c|}{ No } & & \\
\hline & Number & $\%$ & Number & $\%$ & Number & $\%$ & Number & $\%$ & & \\
\hline Meditation & 111 & 72.1 & 43 & 27.9 & 52 & 83.9 & 10 & 16.1 & 7.719 & 0.052 \\
\hline Boodipuja & 141 & 91.6 & 13 & 8.4 & 62 & 100 & 0 & 0 & 64.937 & 0.000 \\
\hline Pirith Chanting & 138 & 89.6 & 16 & 10.4 & 42 & 67.7 & 20 & 32.3 & 49.64 & 0.000 \\
\hline God Blessing & 151 & 98.1 & 3 & 1.9 & 62 & 100 & 0 & 0 & 31.212 & 0.000 \\
\hline $\begin{array}{l}\text { Belief \& } \\
\text { superstition }\end{array}$ & 44 & 28.6 & 110 & 71.4 & 42 & 67.7 & 20 & 32.3 & 133.306 & 0.000 \\
\hline
\end{tabular}


Table 9.2: Religious practice of Catholics

\begin{tabular}{|c|c|c|c|c|c|c|c|c|c|c|}
\hline \multirow[t]{3}{*}{ Practice } & \multicolumn{4}{|c|}{ Fertile (71) } & \multicolumn{4}{|c|}{ Sub-fertile (24) } & \multirow[t]{3}{*}{ Test statistics } & \multirow[t]{3}{*}{ P-Value } \\
\hline & Yes & & No & & Yes & & No & & & \\
\hline & Number & $\%$ & Number & $\%$ & Number & $\%$ & Number & $\%$ & & \\
\hline Praying & 70 & 98.6 & 1 & 1.4 & 24 & 100 & 0 & 0 & 1.032 & 0.794 \\
\hline God Blessing & 69 & 97.2 & 2 & 2.8 & 24 & 100 & 0 & 0 & 25.255 & 0.000 \\
\hline
\end{tabular}

Table 9.3: Religious practice of Hindus

\begin{tabular}{|c|c|c|c|c|c|c|c|c|c|c|}
\hline \multirow[t]{3}{*}{ Practice } & \multicolumn{4}{|c|}{ Fertile (43) } & \multicolumn{4}{|c|}{ Sub-fertile (14) } & \multirow[t]{3}{*}{ Test statistics } & \multirow[t]{3}{*}{ P- Value } \\
\hline & Yes & & No & & Yes & & No & & & \\
\hline & Number & $\%$ & Number & $\%$ & Number & $\%$ & Number & $\%$ & & \\
\hline God Blessing & 43 & 100 & 0 & 0 & 14 & 100 & 0 & 0 & 28.53 & 0.000 \\
\hline
\end{tabular}

Table 9.4: Religious practice of Islam

\begin{tabular}{|c|c|c|c|c|c|c|c|c|c|c|}
\hline \multirow[t]{3}{*}{ Practice } & \multicolumn{4}{|c|}{ Fertile (52) } & \multicolumn{4}{|c|}{ Sub-fertile (5) } & \multirow[t]{3}{*}{ Test statistics } & \multirow[t]{3}{*}{ P-Value } \\
\hline & Yes & & No & & Yes & & No & & & \\
\hline & Number & $\%$ & Number & $\%$ & Number & $\%$ & Number & $\%$ & & \\
\hline Praying & 52 & 100 & 0 & 0 & 5 & 100 & 0 & 0 & 0.754 & 0.912 \\
\hline God Blessing & 51 & 98.1 & 1 & 1.9 & 5 & 100 & 0 & 0 & 12.345 & 0.006 \\
\hline
\end{tabular}

\section{Discussion}

This study demonstrated that majority of women in fertile group were in the age category of 25-29 years and the previous study, conducted in Sri Lanka have shown the same result(9). The mean age of marriage of female in Sri Lanka is 23.4 years(17). But in this study it was a 25 and 26.5 years for fertile and sub-fertile women respectively. Differentiation according to ethnicity could not be observed between Tamil and Sinhala but percentage of Muslim women in sub-fertile group was comparatively low. Moreover it has been showed by one study that Muslims have high fertility than other ethnic group in Sri Lanka(18). Majority of women of fertile and sub-fertile groups are A/L qualified and percentage is equal for both groups (45\%). There was no anyone with post graduate qualification in sub-fertile group and 
percentage of women with education qualification, upper than $A / L$ was higher among fertile group. But some previous studies showed that level of education of women affect in three fertility outcomes, childlessness, timing of children, and number of children(19). In spite of that another study have stated that there is no association between level of education and knowledge on fertility(20).

Sub-fertile women had high usage of family planning, and oral contraceptives and condoms are the most common methods. But we did not observe the association between years of sub-fertility and family planning usage (Independent sample T test). The most probable reason of that was sub-fertility has a complex aetiology and time for sub-fertility is depend on lot of confounding factors. Although national Contraceptive Prevalence Rate (CPR) in Sri Lanka is $65 \%$, it did not affect to the sub-fertility(21). Furthermore few studies have demonstrated that both condom usage and oral contraceptives can preserve fertility of women $(22,23)$. The mean value of BMI of sub-fertile women was in the healthy range but it was 23.4 for fertile women as well as the percentage of obese women was high among fertile than sub-fertile (30\% and $10.5 \%$ ). But conversely previous studies have stated that overweight and obesity of women had poor reproductive outcomes $(24,25)$. In this study, participants were measured only for general obesity not for the abdominal obesity, as well as certain study have mentioned that abdominal obesity have more adverse effect on fertility(26). Moreover one previous study have been stated the need for more intervention to reduce the BMI to increase the fertility of young women(27).

This study compared the moderate and vigorous physical activities of fertile and sub-fertile women and it demonstrated that sub-fertile women had higher MET of vigorous and moderate physical activities than fertile women. The most common vigorous physical activities were cycling, aerobics, construction works and involved day today activities in high intensities. This was supported by previous study and it had been concluded that increased frequency, duration, and intensity of physical activity were associated with increased sub-fertility(28). In spite of that most of women involved the moderate physical activities like, light weight lifting, aerobics, washing cloths and other day today activities. Further, we found that there was a $59 \%$ fertile woman live with extended family. Hence the domestic and day today activities are shared with family members and therefore opportunity to involve the physical activity is low in extended family. But One previous study stated that women who involved moderate physical activity has took relatively short duration to get pregnant than who did not involve(29). As well as another study concludes that moderate physical activities improve the fertility regardless the $\mathrm{BMI}(30)$. Walking is an important moderate physical activity because anybody can easily involve and considerable amount of calories can be burned. Therefore walking was analysed separately, and it had been found that MET of walking of sub-fertile women was higher than fertile women. The mean tank of total sitting time was not significantly different between two groups. But total sitting time was associated with the occupation of both groups. The occupations, way of transport, and hobbies of fertile women were more sedentary than sub-fertile. Moreover reading newspaper, and novels, entertains with music, watching television, and involving other screen based hobbies were the dominant sedentary activities of both groups. But fertile women spent more times for those activities than sub-fertile and house wives of both groups had more sedentary time than other professions. This finding is similar to some previous studies which was stated that sedentary hobbies are not associated with the fertility of the women $(31,32)$. 
To find the association between Second Hand Smoking (SHS) and sub-fertility, O.R was calculated $(O . R=1.3)$. O.R 1.3 means that woman who expose to SHS has 1.3 times higher chance to be sub-fertile than woman who does not expose to SHS. The findings have been demonstrated by previous studies. One study concluded that if women are exposed to SHS from more than two years they have the problem with conserving and early menopause(33). The deleterious effects of smoking for the fertility of women are obvious and it has been proved with several epidemiological studies $(34,35)$ Another study states that risk of SHS s similar to the active smoking and women and children are more vulnerable for SHS(36). But conversely another study showed that SHS is not appreciably associated with fertility of women(37).

Women in both groups in our study did not expose to tobacco smoke for a long period, as well as their frequency of exposure and duration was very low. Instead of that most of women exposed to SHS at their home environment and therefore they have opportunity to avoid the harmful exposure. Sleep is a critical component to health and well-being. Therefore number of sleeping hours was taken in to consideration in our study. But we identified there was a majority of sub-fertile women had not good restful sleep at night and one study has found that quality of sleep and duration of sleep is associated with the level of stress(38). As well as another two studies have stated that mental stress increase the risk of subfertility $(39,40)$. This was reinforced by two previous studies and it has been stated that poor sleep cause to irregularities of menstrual cycle which cause to sub-fertility $(41,42)$.

Hobbies were analysed to find the association for fertility of two groups because most of hobbies cause to reduce the stress and improve the fertility by regulating the healthy hormones. Some studies have showed that listening to music can reduce emotional distress and improve the fertility(43)(42). In this study odds ratio was calculated ( $(\mathrm{R}=0.6)$ to find the association between music and sub-fertility and the result indicated that entertainment with music is a protective factor to increase the fertility. Furthermore we found that going picnic and involving social works were high among fertile women than sub-fertile. These events help to detachment of day today busy work and it is great opportunity to get together with friends and family members. One study showed that tourism has the positive effect on life satisfaction and reduce the level of stress(44). Petting animal was not the hobby of majority of women in both groups and comparatively the percentage of fertile women was high. But some literature pointed out that petting animal, provide an unconditional source of affection, enhance self-esteem, and emotional stability, reduce the feeling of loneliness and isolation and help to people to socialize (45).

Religious practices help to cope-up the stressful life situations and therefore stress releasing religious practices were analysed with fertile and sub-fertile groups. But lot of practices are inherent to the particular religion and people are adhering to follow according their own religious beliefs. But one previous study showed that any religious practice can help to reduce the distress of sub-fertile women (46). Our study demonstrated that the percentage of Sub-fertile women, who involved the meditation, were higher than percentage of fertile women. Involving meditation help to be mindfulness and it pave the way to reduce the stress(47). Another study indicated that meditation help to reduce the stress due to fertility problems of women(40). 
According to our study findings, religious practices, such as boodi puja, pirith chanting, and belief and superstition were very common to Buddhist women and those were analyzed only for Buddhists. It was found that sub-fertile women follow the belief and superstition rather than fertile women. A broad range of human behaviour is influenced by religion and religious practices which are imperative to affect the fertility of human being. Hence the women who expects to achieve the nobles position in the world (motherhood) is behaved by their emotional involvement rather than rational way. Consequently subfertile women involve lot of belief and superstition activities. Meditation is the most common practice among both group of Buddhist women and similarly praying is the dominant religious practice among catholic women of both fertile and sub-fertile women. Almost all the Hindu and Islam women involved the invoking blessing of god and praying respectively. In spite of the religion, Invoking blessing of god was the most common practice of all the women in two groups in our study. In general sub-fertile women refer to the religious practices than fertile. Moreover some previous studies have stated that yoga can improve the reproductive health including fertility $(48,49)$. But least percentages of women in both groups involve in yoga.

Even though lifestyle factors have great impact on fertility, certain important factors like dietary habits were excluded in our study due to resource constrains. Therefore studies on fertility should be more concentrated on behavioural factors including diets, exposure to the electromagnetic field, radiation and toxic chemicals in foods in future studies in Sri Lanka. Furthermore we assessed the physical activity through a questionnaire. But the accuracy of data is depending on the recall ability of the participants and this was another limitation of the study. Objective measurements by accelerometers or direct observations are suggested to overcome such drawbacks.

\section{Conclusion}

In conclusion the exposure to the passive smoking was a risk factor for the fertility and conversely entertain with music was the protective factor for the fertility. To avoid the vigorous physical activities is suggested to reduce the risk of sub-fertility of women who expecting a baby and there was no evidence to support the association between moderated physical activity and sedentary hobbies with fertility. Newly married and sub-fertile couples should be awared on the importance of the life style factors on fertility. In spite of that they should be empowered with necessary skills and therefore training programmes on moderate physical activities and yoga exercise should be conducted by the primary healthcare providers in the country. Finally existence of god and blessing of god is strongly believed by the people, disregarding their religion.

\section{Abbreviations}

BMI: Body Mass Index

MET: Metabolic Equivalent Task 
IQR: Inter Quintile Range

SD: Standard Deviation

OD: Odds Ratio

Cl: Confidence Interval

TFR: Total Fertility Rate

CSHW: Castle Street Hospital for Women

DSHW: De Soysa Hospital for Women

A/L: Advance Level

CPR: Contraceptive Prevalence Rate

SHS: Second Hand Smoking

\section{Declarations}

\section{Ethical Approval}

Ethical approval was obtained from the Ethical Review Committee of the Faculty of Medicine, University of Kelaniya (P/03/01/2019). The confidentiality of the acquired data was maintained throughout the study.

\section{Consent for publication}

Not applicable

\section{Availability of data and materials}

The data sets used and/or analyzed during the current study are available from corresponding author on reasonable request.

\section{Conflict of Interest}

The authors have declared that they have no competing interest.

\section{Authors' contribution}

MPM Conceived the study, designs the study, development of the protocol, analyzes the data, interpretation of the data and wrote the manuscript. BK Guided to design the study, development of the 
protocol, analyze the data and review the manuscript. CD, KL \& KI collected the data. All authors red and approved the final manuscript.

\section{Funding}

No funding or sponsoring organization was involved in the carrying out of this work

\section{Acknowledgement}

Researchers wish to express sincere gratitude towards the participants of the study and staff of DSHW and CSHW.

\section{References}

1. Moridi A, Roozbeh N, Yaghoobi H, Soltani S, Dashti S, Shahrahmani N, et al. Etiology and risk factors associated with infertility. Int J Women's Heal Reprod Sci [Internet]. 2019;7(3):346-53. Available from: https://doi.org/10.15296/ijwhr.2019.57

2. Al-Turki HA. Prevalence of primary and secondary infertility from tertiary center in eastern Saudi Arabia. Middle East Fertil Soc J. 2015 Dec 1;20(4):237-40.

3. El-saharty S, Ohno N, Sarker I, Secci F. South Asia: Maternal and Reproductive Health at a Glance. 2014;(January):1-4.

4. Palihawadana $T$, Wijesinghe $P$, Seneviratne $H$. Aetiology of infertility among females seeking treatment at a tertiary care hospital in Sri Lanka. Ceylon Med J [Internet]. 2012 Jun 30 [cited 2018 Jun 27];57(2):79. Available from: https://cmj.sljol.info/article/10.4038/cmj.v57i2.4461/

5. Zegers-Hochschild F, Adamson GD, De Mouzon J, Ishihara O, Mansour R, Nygren K, et al. The International Committee for Monitoring Assisted Reproductive Technology (ICMART) and the World Health Organization (WHO) Revised Glossary on ART Terminology, 2009. Hum Reprod. 2009;24(11):2683-7.

6. Khan A, Barkat N, Afzal S. Responsibility, Prevalence and major factors of infertility. A cross-sectional study in Karachi. Int J Endorsing Heal Sci Res [Internet]. 2015 [cited 2018 Jun 27];3(2). Available from: http://oaji.net/articles/2015/1909-1439990472.pdf

7. Sharma R, Biedenharn KR, Fedor JM, Agarwal A. Lifestyle factors and reproductive health: taking control of your fertility. Reprod Biol Endocrinol [Internet]. 2013 Jul 16 [cited 2018 Jul 12];11:66. Available from: http://www.ncbi.nlm.nih.gov/pubmed/23870423

8. Li J, Long L, Liu Y, He W, Li M. Effects of a mindfulness-based intervention on fertility quality of life and pregnancy rates among women subjected to first in vitro fertilization treatment. Behav Res Ther 
[Internet]. 2016 Feb 1 [cited 2020 Mar 5];77:96-104. Available from:

http://www.ncbi.nlm.nih.gov/pubmed/26742022

9. Hewabatage PN, Gunawardhana LKMP, Gunarathna MKNS, Bandara EMS, De Silva BSS. REASONS FOR PRIMARY SUB-FERTILITY AMONG COUPLES ATTENDING SUB-FERTILITY CLINICS AT TWO GOVERNMENT HOSPITALS. [cited 2018 Jun 27]; Available from: http://www.ou.ac.lk/ours/wpcontent/uploads/2017/04/B404-E.pdf

10. Senaratne R, Mendis S. Prevention and Control of Noncommunicable Diseases- Think Globally-Act Locally; Lessons from Sri Lanka. Minist Heal Nutr Indig Med Sri Lanka. 2018;xi-xiii, 28-40, 159-68.

11. Use FOR, Young W, Adults M. ( October 2002 ) LONG LAST 7 DAYS SELF-ADMINISTERED FORMAT. 2002;71(October).

12. Katulanda P, Jayawardana R, Ranasinghe P, Sheriff MHR, Matthews DR. Physical activity patterns and correlates among adults from a developing country: the Sri Lanka Diabetes and Cardiovascular Study. 2012;16(9):1684-92.

13. Activity P, Guidelines B, Discussion P, Lanka S. On Sedentary For Public Discussion Presented To Hon . Rajitha Senarathne Ministry Of Health, Nutrition and Indigenous Medicine. 2018;

14. Mohammed F. Investigating the Impact of Walking on humans Health. 2017;(2):132-43.

15. Westoff CF, Koffman DA. The association of television and radio with reproductive behavior. Popul Dev Rev [Internet]. 2011 [cited 2018 May 27];37(4):749-59. Available from: http://www.ncbi.nlm.nih.gov/pubmed/22319772

16. Girdhar S, Sharma S, Chaudhary A, Bansal P, Satija M. An epidemiological study of overweight and obesity among women in an Urban area of North India. Indian J Community Med. 2016;41(2):154-7.

17. Lanka D of C and S of S. The Sri Lankan Women. 2012;1-121.

18. Samarakoon S, Rajapaksa L, Seneviratne HR. Prevalence of primary and secondary infertility in the Colombo District. Ceylon J Med Sci. 2007;45(2):83.

19. Monstad K, Propper C, Salvanes KG. Education and fertility: Evidence from a natural experiment. Scand J Econ. 2008;110(4):827-52.

20. E G, Radhika K, Shivanagoud Patil S, Sneha R. Knowledge and attitude of infertile couples attending rural tertiary care centre. Indian J Obstet Gynecol Res. 2020;7(2):177-81.

21. Statistics $D$ of $C$ and. Family Planning 5 Key Findings. 2016;60. Available from: http://www.statistics.gov.lk/social/DHS_2016a/Chapter5.pdf 
22. Nanayakkara N, Wazil AWM, Gunerathne L, Dickowita S, Rope R, Ratnayake C, et al. Tackling the Fallout From Chronic Kidney Disease of Unknown Etiology: Why We Need to Focus on Providing Peritoneal Dialysis in Rural, Low-Resource Settings. Kidney Int reports [Internet]. 2017 Jan [cited 2017 Nov 15];2(1):1-4. Available from: http://linkinghub.elsevier.com/retrieve/pii/S2468024916301541

23. Mutsaerts MAQ, Groen H, Huiting HG, Kuchenbecker WKH, Sauer PJJ, Land JA, et al. The influence of maternal and paternal factors on time to pregnancy--a Dutch population-based birth-cohort study: the GECKO Drenthe study. Hum Reprod [Internet]. 2012 Feb 1 [cited 2018 Jun 27];27(2):583-93. Available from: http://www.ncbi.nlm.nih.gov/pubmed/22184203

24. Dağ ZÖ, Dilbaz B. Impact of obesity on infertility in women. J Turkish Ger Gynecol Assoc. 2015;16(2):111-7.

25. Silvestris E, de Pergola G, Rosania R, Loverro G. Obesity as disruptor of the female fertility. Vol. 16, Reproductive Biology and Endocrinology. BioMed Central Ltd.; 2018.

26. Kuchenbecker WKH, Groen H, Zijlstra TM, Bolster JHT, Slart RHJ, Van Der Jagt EJ, et al. The subcutaneous abdominal fat and not the intraabdominal fat compartment is associated with anovulation in women with obesity and infertility. J Clin Endocrinol Metab [Internet]. 2010 [cited 2020 Jul 4];95(5):2107-12. Available from: https://pubmed.ncbi.nlm.nih.gov/20200335/

27. Zafar M. Association of body mass index (BMI) and sub-fertility among young women in Karachi, Pakistan. Fertil Sci Res. 2019;6(1):23.

28. Gudmundsdottir SL, Flanders WD, Augestad LB. Physical activity and fertility in women: The NorthTrøndelag Health Study. Hum Reprod. 2009;24(12):3196-204.

29. Wise LA, Rothman KJ, Mikkelsen EM, Sørensen HT, Riis AH, Hatch EE. A prospective cohort study of physical activity and time to pregnancy. Fertil Steril [Internet]. 2012 May [cited 2018 Jun 14];97(5):1136-42.e1-4. Available from: http://www.ncbi.nlm.nih.gov/pubmed/22425198

30. Wise LA, Rothman KJ, Mikkelsen EM, Sorensen HT, Riis AH, Hatch EE. A prospective cohort study of physical activity and time to pregnancy. Fertil Steril. 2012;97(5).

31. Gaskins AJ, Williams PL, Keller MG, Souter I, Hauser R, Chavarro JE. Maternal physical and sedentary activities in relation to reproductive outcomes following IVF. Reprod Biomed Online [Internet]. 2016;33(4):513-21. Available from: http://dx.doi.org/10.1016/j.rbmo.2016.07.002

32. Foucaut AM, Faure C, Julia C, Czernichow S, Levy R, Dupont C. Sedentary behavior, physical inactivity and body composition in relation to idiopathic infertility among men and women. PLoS One. 2019;14(4):1-15.

33. Misailidi M, Tzatzarakis MN, Kavvalakis MP, Koutedakis Y, Tsatsakis AM, Flouris AD. Instruments to assess secondhand smoke exposure in large cohorts of never smokers: the smoke scales. PLoS One 
[Internet]. 2014 [cited 2018 Aug 12];9(1):e85809. Available from:

http://www.ncbi.nlm.nih.gov/pubmed/24465719

34. Hackshaw A, Rodeck C, Boniface S. Maternal smoking in pregnancy and birth defects: a systematic review based on 173687 malformed cases and 11.7 million controls. Hum Reprod Update [Internet]. 2011 [cited 2020 Jun 22];17(5):589-604. Available from: https://academic.oup.com/humupd/article-abstract/17/5/589/760093

35. Practice Committee of the American Society for Reproductive Medicine T. Smoking and infertility: a committee opinion. Fertil Steril [Internet]. 2012 [cited 2020 Jun 22];98:1400-6. Available from: http://dx.doi.org/10.1016/j.fertnstert.2012.07.1146

36. Mostafa RM. Dilemma of women's passive smoking. Vol. 6, Annals of Thoracic Medicine. 2011. p. 55-6.

37. Radin RG, Hatch EE, Rothman KJ, Mikkelsen EM, Sørensen HT, Riis AH, et al. Active and passive smoking and fecundability in Danish pregnancy planners. Fertil Steril [Internet]. 2014 Jul [cited 2018 Jul 7];102(1):183-191.e2. Available from: http://www.ncbi.nlm.nih.gov/pubmed/24746741

38. Herawati K, Gayatri D. The correlation between sleep quality and levels of stress among students in Universitas Indonesia. Enferm Clin. 2019;29.

39. Rooney KL, Domar AD. The relationship between stress and infertility. Dialogues Clin Neurosci [Internet]. 2018 Mar [cited 2018 Sep 12];20(1):41-7. Available from:

http://www.ncbi.nlm.nih.gov/pubmed/29946210

40. Lynch CD, Sundaram R, Maisog JM, Sweeney AM, Buck Louis GM. Preconception stress increases the risk of infertility: Results from a couple-based prospective cohort study-the LIFE study. Hum Reprod. 2014;29(5):1067-75.

41. Kloss JD, Perlis ML, Zamzow JA, Culnan EJ, Gracia CR. Sleep, sleep disturbance, and fertility in women. Sleep Med Rev [Internet]. 2015 Aug [cited 2018 May 27];22:78-87. Available from: http://www.ncbi.nlm.nih.gov/pubmed/25458772

42. White ND. Influence of Sleep on Fertility in Women. Am J Lifestyle Med. 2016;10(4):239-41.

43. Aba YA, Avci D, Guzel Y, Ozcelik SK, Gurtekin B. Effect of music therapy on the anxiety levels and pregnancy rate of women undergoing in vitro fertilization-embryo transfer: A randomized controlled trial. Appl Nurs Res [Internet]. 2017;36(October):19-24. Available from: http://dx.doi.org/10.1016/j.apnr.2017.05.005

44. Chen CC, Petrick JF, Shahvali M. Tourism Experiences as a Stress Reliever: Examining the Effects of Tourism Recovery Experiences on Life Satisfaction. J Travel Res. 2016;55(2):150-60. 
45. Shiloh S, Sorek G, Terkel J. Reduction of state-anxiety by petting animals in a controlled laboratory experiment. Anxiety, Stress Coping. 2003;16(4):387-95.

46. Aflakseir A, Mahdiyar M. The role of religious coping strategies in predicting depression among a sample of women with fertility problems in Shiraz. J Reprod Infertil. 2016;17(2):117-22.

47. Fard TR, Kalantarkousheh M, Faramarzi M. Effect of mindfulness-based cognitive infertility stress therapy on psychological well-being of women with infertility. Middle East Fertil Soc J [Internet]. 2018;23(4):476-81. Available from: https://doi.org/10.1016/j.mefs.2018.06.001

48. Dumbala S, Bhargav H, Satyanarayana V, Arasappa R, Varambally S, Desai G, et al. Effect of yoga on psychological distress among women receiving treatment for infertility. Int J Yoga. 2020;13(2):115.

49. Darbandi S, Darbandi M, Khorshid HRK, Sadeghi MR. Yoga can improve assisted reproduction technology outcomes in couples with infertility. Altern Ther Health Med. 2018;24(4):50-5.

\section{Figures}

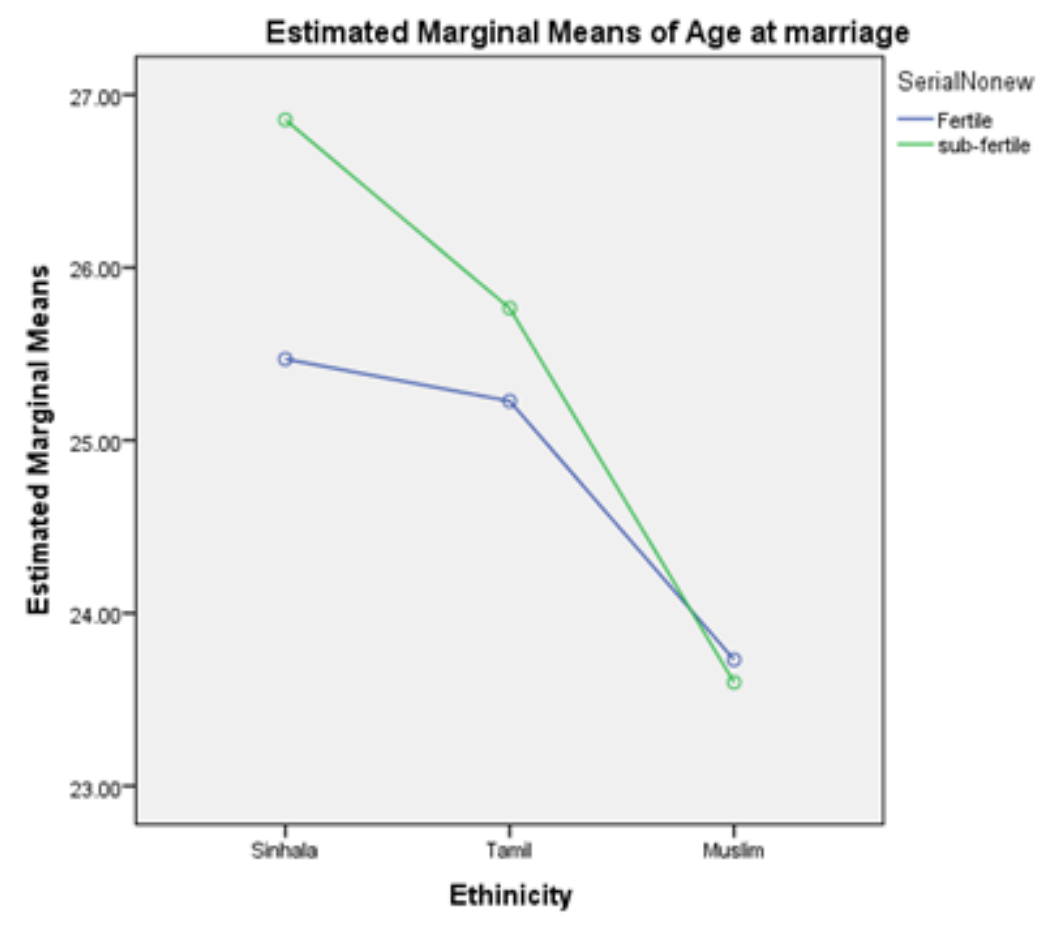

\section{Figure 1}

Ethnicity and mean age at marriage of participants 


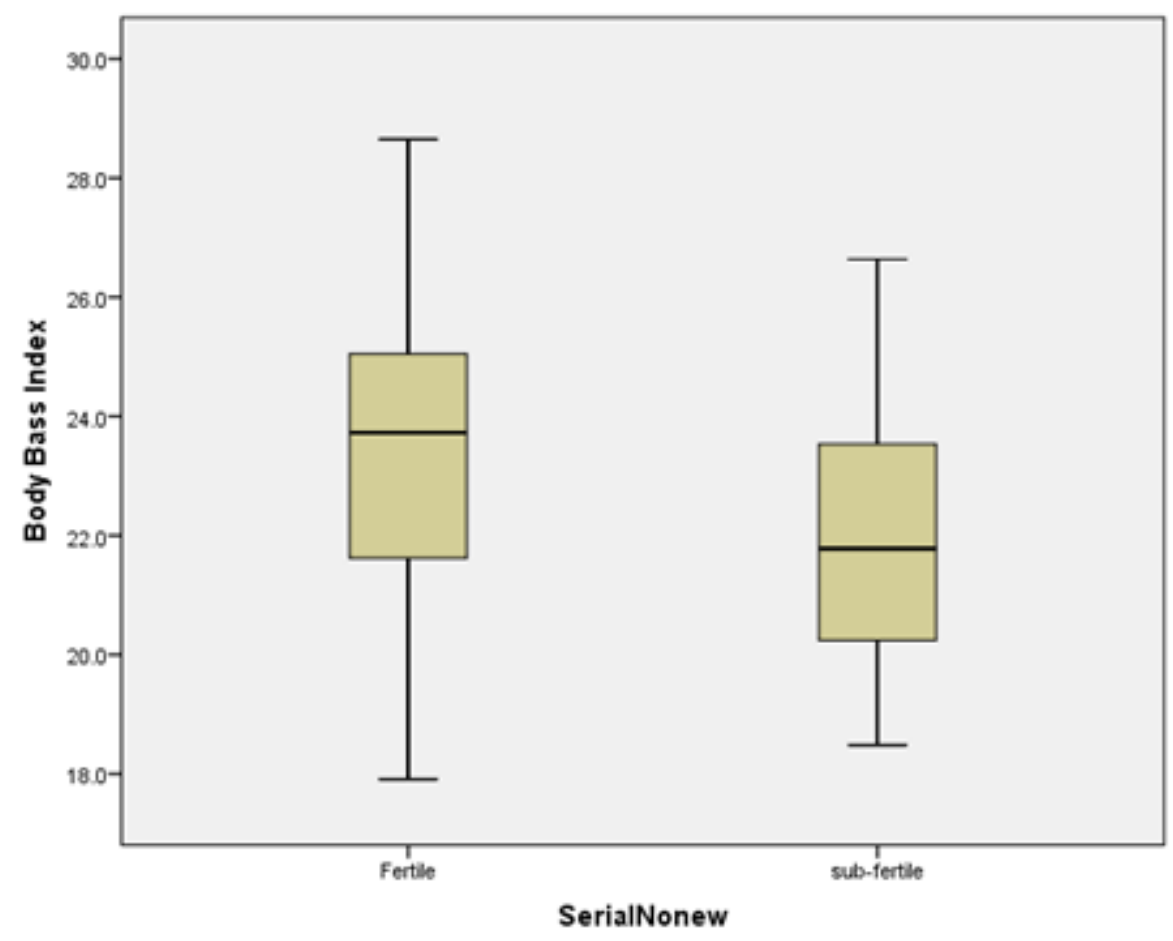

Figure 2

Body Mass Index (BMI) of the participants

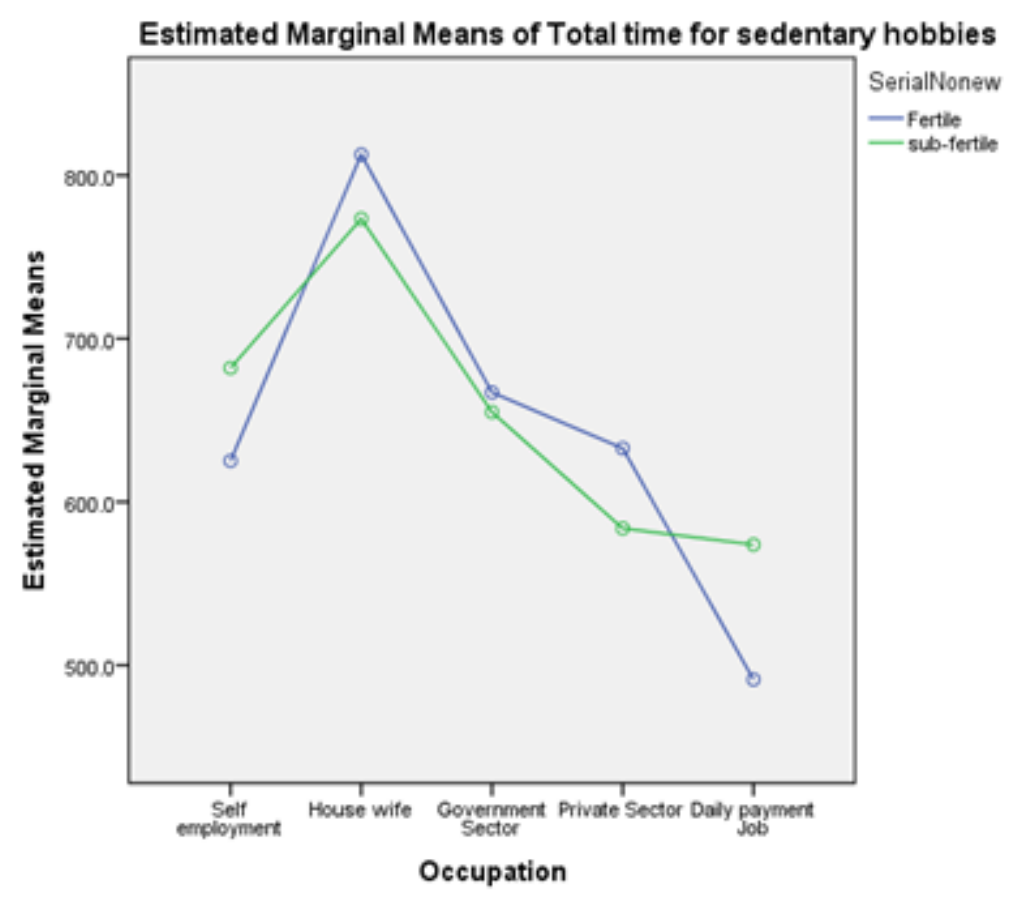

Figure 3

Sedentary hobbies of the women according to profession 